\title{
Does the hospitalization immersion experience improve medical students' understanding of patients' perspectives? A qualitative study
}

\author{
Makoto Kikukawa', Kikuko Taketomi ${ }^{2}$ and Motofumi Yoshida ${ }^{3}$ \\ ${ }^{1}$ Department of Medical Education, Faculty of Medical Sciences, Kyushu University, Fukuoka, ${ }^{2}$ School of Nursing, \\ Sapporo City University, Sapporo, and ${ }^{3}$ Medical Education, Department of Social Medical Sciences, Graduate \\ School of Medicine, International University of Health and Welfare, Narita, Japan
}

Purpose: Although many studies have assessed the impact of interventions to increase medical students' empathy by improving their understanding of patients' perspectives and feelings, the impact of hospitalization experiences remains unclear.

Methods: Fifth-year medical students at Kyushu University from 2009-2013 participated in a 2-day/1-night course to provide a hospitalization experience. After the course, participants answered an online, anonymous, open-ended questionnaire created by the authors.

Results: Of 488 participants, 462 provided responses (95\% response rate), which were evaluated by thematic analysis. Students understood inpatients not only through their own hospitalization experience, but also through observations of and conversations with the inpatients they encountered, from a shared perspective of both. Students experienced the realities of hospital life, stress and psychological states of being an inpatient, and psychological pressure from physicians. In addition, students observed the distress of other inpatients and dedication of medical staff. Furthermore, through communication with these inpatients, students understood other inpatients' anxiety about illness and empathy as one of the requirements of health care providers from the patients' perspective. Conclusion: This qualitative study investigated the effectiveness of a course on the hospitalization experience. Results showed that medical students understood the perspectives, distress, and anxiety of being an inpatient, not only from their own experiences but also from observation and communication with other inpatients they encountered during their hospitalization. This experience appeared to be an effective teaching strategy for enhancing medical students' empathy by improving their understanding of patients perspectives and feelings.

Key Words: Empathy, Hospitalization, Medical students

\section{Introduction}

The physician-patient relationship is the foundation of medicine [1], and empathy is considered to be vital for physicians to establish effective physician-patient rela- tionships and is a crucial component of professionalism [2-5]. Empathy is defined as a predominantly cognitive attribute that involves an understanding of experiences, concerns, and perspectives of another person, combined with a capacity to communicate this understanding [6]. The positive impact of empathetic health care in-
Received: March 16, $2021 \bullet$ Revised: April 1, 2021 • Accepted: April 2, 2021 Corresponding Author: Makoto Kikukawa (https://orcid.org/0000-0002-7903-6430) Department of Medical Education, Faculty of Medical Sciences, Kyushu University, 3-1-1 Maidashi, Higashi-ku, Fukuoka, 812-8582, Japan

Tel: +81.92.642.6186 Fax: +81.92.642.6188 email: kikukawa.makoto.892@m.kyushu-u.ac.jp
Korean J Med Educ 2021 Jun; 33(2): 97-106 https://doi.org/10.3946/kjme.2021.191

eISSN: 2005-7288

(C) The Korean Society of Medical Education. All rights reserved. This is an open-access article distributed under the terms of the Creative Commons Attribution Non-Commercial License (http:// creativecommons.org/licenses/by-nc/3.0/), which permits unrestricted non-commercial use, distribution, and reproduction in any medium, provided the original work is properly cited. 
teractions on patient outcomes has been reported $[7,8]$. Physicians' empathetic communication contributes toward patient compliance [9-11]. Empathetic health care interactions resulted in reduced rates of infection, improved wound healing, higher cancer survival rates, and a reduction in diabetes complications [12].

Because empathetic communication can have a substantial impact on the physician-patient relationship [13-16], undergraduate medical education in many countries is designed to educate students to become empathetic physicians [1]. However, despite these medical education endeavors, empathy levels are shown to decrease during undergraduate medical education [17]. Although various methods for enhancing empathy have been implemented in medical education [18], no consensus has been reached regarding the optimal methods for teaching it $[2,19]$.

As one effective teaching method, experiential learning has received substantial attention in the literature to understand patients' perspectives and feelings as essential components of empathy [4]. For example, wearing dry and then wet undergarments while confined to a wheelchair promotes empathy for patients with bladder control problems [20]. Experiential learning is an instructional strategy based on the notion that students learn best by personally engaging in an activity or encounter [21].

However, only one study to date has reported the effectiveness of a hospitalization experience as an experiential learning intervention [22]. In that study, Wilkes et al. reported that hospitalization experience had a substantial impact on participating second-year medical students before clinical immersion [22]. Therefore, the present study focused on medical students involved in clinical training to develop a course involving hospitalization experience, by applying Kolb's experiential learning model to develop students' empathy by improving their understanding of patients' perspectives and feelings [23]. This theory involves a four-stage cycle with distinct adaptive learning modes: concrete experience, reflection, abstract conceptualization, and active experimentation [23]. Based on this foundation, the objective of the current study was to qualitatively investigate the effects of a hospitalization experience course on empathy among undergraduate medical students in the clinical training stage.

\section{Methods}

\section{Intervention}

The Faculty of Department Medical Education delivered the course as a part of clinical rotation curriculum in the fifth-year for medical students from 2009 to 2013. All the course syllabi, including the one for this course, were distributed to the students at the beginning of the school year, so they knew in advance what kind of practical training they would be receiving. Students were asked to notify us in advance if they had any requests, such as room preference, meals (allergies, and so forth), or reasonable accommodation.

Attending doctors in charge of the ward explained to the inpatients who would be in the same rooms as the students during the hospitalization experience and obtained consent from the inpatients in advance. We also requested that the attending physicians or nurses in charge of the ward consider any psychological burdens carefully for the medical students. If any problems arose, we made sure to have them contact the medical education faculty (even during nighttime).

The course started at $10 \mathrm{AM}$ and ended the next day at 2:30 PM with four to five medical students per week. In the orientation, the faculty explained that the 


\begin{tabular}{|c|c|}
\hline Time & Schedule \\
\hline 10:00-10:30 & $\begin{array}{l}\text { (1) Students received an orientation with an explanation of the course and relevant precautions from the faculty } \\
\text { before their inpatient experience. }\end{array}$ \\
\hline 10:30-11:00 & $\begin{array}{l}\text { (2) Students completed a pledge form and hospital gown application form in the same way as other hospitalized } \\
\text { patients. }\end{array}$ \\
\hline \multirow[t]{4}{*}{$\begin{array}{l}11: 00-13: 00 \text { of the } \\
\text { next day }\end{array}$} & $\begin{array}{l}\text { (3) Students completed a mock hospitalization procedure at the Kyushu University Hospital admission reception } \\
\text { desk. }\end{array}$ \\
\hline & $\begin{array}{l}\text { (4) Hospitalization, students were subject to ward management, wore a hospital gown, and experienced the ward } \\
\text { rules regarding resting, eating, and bathing. }\end{array}$ \\
\hline & $\begin{array}{l}\text { (5) Students underwent formal orientation from the nursing staff. Height and weight measurement, assessment } \\
\text { of vital signs, urine sampling, and examination at the time of admission by the ward physician. }\end{array}$ \\
\hline & $\begin{array}{l}\text { (6) Students were encouraged to communicate with other patients in the same room; there were on an average } \\
\text { three patients per room. }\end{array}$ \\
\hline 13:00-13:30 & $\begin{array}{l}\text { (7) After their hospitalization, students met to reflect on the experience and share their experiences with each } \\
\text { other as well as the faculty in a discussion. }\end{array}$ \\
\hline
\end{tabular}

objective of this course was to understand inpatients' perspectives and feelings via the hospitalization experience. After their hospitalization, the students met to reflect on and share their experiences with each other, as well as with faculty, in a discussion based on the course objective. The schedule of the hospitalization experience course is listed in Table 1.

\section{Patient and public involvement}

Patients or the public were not involved in the design, conduct, reporting, or dissemination plans of this study.

\section{Participants}

Fifth-year medical students at Kyushu University from 2009 to 2013 were recruited for the course. Several students did not participate in the hospitalization experience because of the following reasons: (1) actual hospitalization after entering university (given they already had experienced actual hospitalization); (2) illness or an unexpected accident (schedules were rearranged to accommodate for such incidents as much as possible); (3) hospital beds were fully occupied and could not be prepared (schedules were rearranged to accommodate for such incidents); and (4) did not agree

\begin{tabular}{ccc}
\hline \multicolumn{3}{c}{ Table 2. Number of Students in Each School Year } \\
\hline $\begin{array}{c}\text { School } \\
\text { year }\end{array}$ & $\begin{array}{c}\text { No. of recruited } \\
\text { students }\end{array}$ & $\begin{array}{c}\text { No. of nonparticipating } \\
\text { students }\end{array}$ \\
\hline 2009 & 101 & 2 \\
2010 & 105 & 5 \\
2011 & 103 & 6 \\
2012 & 90 & 4 \\
2013 & 113 & 7 \\
Total & 512 & 24 \\
\hline
\end{tabular}

to the hospitalization experience.

Even if they did not participate in the hospitalization experience for any reason, we asked them to participate in the orientation and the discussion for reflection. In total, 488 of the 512 medical students participated in this course, and 462 of 488 provided responses (95\% response rate). The number of participants is shown in Table 2.

\section{Procedure}

During one clinical rotation in the fifth-year, four to five medical students per week were allocated to the Department of Medical Education. The faculty (one of the three authors) explained the objective of this course and the survey study in detail, and medical students were asked to read the participant sheet, both regarding the hospitalization experience and the survey, and provided 
the opportunity to ask questions about the study before providing written consent. The faculty then provided an orientation schedule, as described in the Intervention section. The following day, the faculty asked participants in the hospitalization experience to complete an anonymized online survey using Blackboard software. To minimize the bias, the faculty explained that the survey was completely anonymous and voluntary, and therefore the students' answers did not influence their course grade, even if they did not answer any questions. Because we were deeply convinced of the academic value of the data after conducting this course, we asked the institutional review board of Kyushu University to carefully review this study, which they subsequently approved (institutional review board approval no., 2020-271).

\section{Data analysis}

A survey with open-ended questions was used to capture data from all medical students who underwent the intervention and consented to participate, instead of conducting in-depth interviews with only a subsample of participants. This approach allowed the generation of rich participant responses that were not constrained by the researchers' views and allowed participants the opportunity to express their beliefs using their own language and terms. Thematic analysis was used to analyze qualitative data, including responses to openended survey data [24]. This approach is considered to be a useful method for analyzing qualitative data, facilitating the organization of data, and capturing valuable information.

In total, 1,410 comments were collected. The first author initially checked and confirmed that there was no personal information in any of the comments. Responses were analyzed using thematic analysis [24]. During the first 2 years of data collection, all responses to open- ended comments were coded independently by the first author and second author to identify emerging themes, using open coding to produce an initial set of themes and subthemes. This set of themes and subthemes was then applied to all other participant responses. Recurring themes were identified, and codes were generated in the form of phrases to represent important data. For the current study, coding was implemented manually. Spreadsheet software (Excel ver. 2016; Microsoft Corp., Redmond, USA) was used to assist with organizational aspects of coding. Throughout this process, themes and subthemes were revised by the two coders and any disagreements were resolved through discussion. Data from the final set of themes and subthemes were compared and evaluated to derive a higher-order synthesis of the findings by authors who are educational experts. Data, which was password protected for security, were shared among the authors.

\section{Open-ended questionnaire}

To measure the effectiveness of this course, the open-ended questionnaire was created by the authors who are educational experts and qualified by the academic institutions. The first author has master's degree and doctorate of medical education. The second author has doctorate of medical education. The third author is a professor of Department of Medical Education at Kyushu University, Japan. (Now the third author has moved to International University of Health and Welfare, Narita, Japan.) The questionnaire content follows: (1) Please give specific experiences and describe your impressions of what you felt or noticed for the first time during this experience in hospital. (2) What did you think of the nursing staff and how they interacted with you? (3) In the discussion after your experience, what did you reflect on? 


\section{Results}

Medical students understood inpatients not only through their own experience as a patient during their hospitalization experience, but also through observation and conversations with the inpatients they encountered, from a shared perspective as both being patients. The following themes and subthemes were coded. Themes and subthemes are shown in Table 3.

\section{Understanding patients through personal experience}

\section{1) Realities of hospital life}

The medical students experienced various realities of hospital life, such as communal living and the distress of undergoing examinations and treatments. The realities of inpatient life consisted mainly of communal hardships, such as lights being turned off too early, being unable to sleep because of the snoring of other patients. This theme was exemplified by the following comments.

"I had to sleep at 9:00 PM. It was too early"

"I found it hard to sleep in a room because of other people's snoring."

\section{2) Stress and psychological state of the inpatients}

The medical students experienced the stress and psychological state of the inpatients, specifically, the mental strain of being in an unusual situation, forethought for other inpatients, loneliness, and the pressure of exposure to being the patient for physicians' rounds. This theme was illustrated by the following comments.

\footnotetext{
"Shared rooms are surprisingly stressful because I can hear the patients next to me talking and making noise, which is surprisingly stressful."

"I could see firsthand the loneliness of being in the hospital."
}

\section{3) Psychological pressure from physicians}

The medical students understood the psychological pressure that inpatients felt from physicians. They realized that the view of physicians from the perspective of a patient in a hospital room was completely different from that of a medical student when attending rounds. As patients, medical students felt stressed by the psychological pressure of experiencing physicians' rounds as a patient. This theme is illustrated by the following comment:

"I felt quite oppressed when I was lying in bed and a lot of doctors were standing and looking at me."

Table 3. Themes and Subthemes
\begin{tabular}{ll}
\multicolumn{1}{c}{ Themes } & \multicolumn{1}{c}{ Subthemes } \\
\hline 1. Understanding patients through personal experience & (1) Realities of hospital life \\
& (2) Stress and psychological state of the inpatients \\
2. Understanding through observation from the patient's perspective & (3) Psychological pressure from physicians \\
3. Understanding inpatients' feelings through conversations with thempatients
\end{tabular}
$\begin{array}{ll}\text { (4) Dedication of medical staff } \\
\text { (6) Anxiety about illness }\end{array}$
$\begin{aligned} & \text { (7) Deep understanding of empathy as one of the requirements } \\
& \text { of health care providers }\end{aligned}$




\section{Understanding through observations from the patient's perspective}

The medical students observed inpatient conditions for patients in the same room. The students' understanding of inpatients was reinforced not only by their own direct experiences but also by their observations of other patients.

\section{1) Distress of inpatients}

The medical students observed inpatients' distress related to their illness. They understood that inpatients in the same situation were encouraging of each other. In addition, medical students understood that inpatients were able to understand each other because they had similar experiences. This theme was described by some medical students who expressed the following views.

\footnotetext{
"A patient next to me seemed to be in pain."

"Patients were very encouraging and caring toward other patients, and I thought they were supporting each other even when they had a painful illness."
}

\section{2) Dedication of medical staff}

The medical students were able to observe the devotion of the hospital staff to care for patients who seemed to be in distress, by staying in the hospital room for long enough to calm the patient. The students understood the importance of the dedication of health care providers, particularly nurses, toward patients in their rooms, not only from their own experiences but also from their observations. This theme was underscored by a medical student expressing the following observation:

"I thought that it was only the nurses who came to the room frequently, and that it might be the nurses, rather than the doctors, who are more aware of the patients' conditions."

\section{Understanding inpatients' feelings through conversations with them}

The medical students appeared to gain a better understanding of the inpatients' situations by direct conversations with these patients, specifically by hearing about their "anxiety about illness" and their "psychological distance from physicians" from the same standpoint as the patients without the shield of a white coat (importantly, medical students wore the same hospital gowns as inpatients during hospitalization).

\section{1) Anxiety about illness}

The students understood how patients' anxiety about their illnesses haunted them by directly hearing the perspectives of these patients. The students understood patients' perspectives more deeply by hearing from patients about their illness experiences while simultaneously experiencing time as a patient. This theme is illustrated by the following comment:

"I was able to actually talk to the patients and learn how anxious they were."

\section{2) Deep understanding of empathy as one of the requirements of health care providers}

Through communication with inpatients, the medical students recognized the importance and requirement for health care providers to understand the feelings, anxiety, and stresses of hospitalized patients, and to pay attention and talk to the patients to put them at ease, empathizing with the patients as much as possible. This theme was described by some medical students, as in the following comments.

\footnotetext{
"It isn't possible to be an empathetic doctor without
} 
understanding the feelings of patients."

"As a health care provider, I felt that I needed to pay attention to how stressed my patients were about what they were feeling when doctors were dealing with patients."

"I understood the importance of being proactive in showing up to my inpatients."

\section{Discussion}

The principal findings were that medical students understood patients' perspectives, distress, and anxiety not only from their own experiences of hospitalization during the course, but also from their observation and communication with the other inpatients. Accordingly, our findings suggested that the hospitalization $\mathrm{ex}^{-}$ perience in clinical course of undergraduate medical education might contribute to enhance student's empathy by improving their understanding of patients' perspectives and feelings because this hospitalization experience appeared to stimulate cognitive attributes that involve an understanding of experiences, concerns, and perspectives of another person [6].

Because empathy is considered an important component of medical professionalism $[5,25,26]$, the development of empathy should be inevitably incorporated into formal education [27]. Therefore, we believe that this course may contribute not only to the enhancement of students' empathy but also to the development of students' professionalism from a broader perspective.

Regarding "understanding patients through personal experience," Wilkes et al. [22] reported that hospitalized medical students expressed a profound loss of privacy, sense of caring, attentive professionalism of nurses, and discomfort after their experience of hospitalization [5], findings that are compatible with some results of the present study. Not mentioned in the previous study were the current study findings that the hospitalization experience allowed medical students to understand the psychological pressure from physicians by direct experience, the inpatients' the distress by observation, and deep understanding of empathy as one of the requirements of health care providers thorough conversation with other patients.

Important differences in results among studies must be addressed. Regarding psychological pressure from physicians and psychological distance from physicians, the cultural differences between this study in Japan and the study of Wilkes et al. [22] in the United States may complicate comparison. Ohtaki [28] reported that, in contrast to the United States, Japanese physician-patient communication is physician-facilitating and physiciandependent in a hierarchical society. In this context, if physicians were not willing to communicate with patients, then patients tended to feel psychological pressure from physicians. Therefore, medical students' perspectives may differ according to their cultural context. Further study is required to examine these differences.

The theme of "understanding through observations from the patient's perspective," has not been reported in the hospitalization experience intervention, which is one of the experimental learning methods reported in literature. We assume that this theme may be similar to the videotaping of encounters with patients, which is one of the different teaching methods of empathy from experimental learning. The videotaping of patient encounters with physicians, nurses, hospital, and office administrators for the purpose of identifying positive and negative interviewing factors is a valuable learning experience for enhancing empathic engagement [6]. We believe, however, that medical students might understand patients' perspectives better from direct obser- 
vation and not from videotaping.

The theme "understanding inpatients' feelings through conversations with them" was also not found in the literature on hospitalization experience. We believe that this is a similar concept to the patient narrative approach, which is one of the different teaching methods for empathy from experimental learning [6]. Several studies showed that medical students increased their empathy by interviewing a patient from his or her perspective $[29,30]$. We believe that this theme may have occurred during the hospitalization experience because of the real-life situation this entails.

Judging from the second and the third themes, the hospitalization experience may have had a substantial impact on students' empathy beyond common experiential leaning framework. The reported experiential learning interventions have not been conducted not in real-life settings. Based on the findings of the present study, the hospitalization experience, involving observations of inpatients, and hearing narratives from inpatients, may have simultaneously facilitated a multilayered understanding of patients because the study was conducted in a real-life setting.

The strengths of this study are as follows. First, we demonstrated that medical students understood patients' perspectives and feelings through the hospitalization experience. Second, variations in the learnings between Japan and US students would occur even with the same teaching strategy of the hospitalization experience. Third, we confirmed that a real-life setting in which a hospitalization experience is provided makes it possible to include the framework of videotaping encounters with patients and patient interview intervention beyond the common experiential learning framework. Further studies are required to explore the effectiveness of hospitalization experiences in a variety of institutions.

The current study has several limitations. First, the design was a single-center study; therefore, the generalizability of findings may be limited, and further studies are required to confirm the representativeness of the results. Second, the survey was administered only after course completion, so the study did not precisely capture the change in medical students' empathy by this course; instead, a pre/post study survey is required to ensure the effectiveness. Third, as this study was conducted using a qualitative method, future studies using quantitative methods are warranted to further validate the data obtained. Although findings suggest that hospitalization experience may provide a useful teaching strategy, further studies of large samples at multiple institutions are needed to evaluate the outcomes in more depth. Such trials should include randomized controlled trials with appropriate control groups.

In conclusion, the hospitalization experience appeared to enhance medical students' understanding of patients' perspectives and feelings, essentially expanding their empathy not only by their own direct experience as patients but also through their observation of and communication with other inpatients. The experience of hospitalization may be an effective teaching strategy.

\section{ORCID:}

Makoto Kikukawa: https://orcid.org/0000-0002-7903-6430; Kikuko Taketomi: https://orcid.org/0000-0003-0295-2630; Motofumi Yoshida: https://orcid.org/0000-0002-6544-8629

Acknowledgements: We thank the medical students who participated in this study. The authors also wish to thank all staff involved in Kyushu University Hospital. Funding: This work was supported by JSPS KAKENHI (grant no., JP17H04097).

Conflicts of interest: No potential conflict of interest relevant to this article was reported.

Author contributions: MK planned the study, collected 
the data and wrote the paper. KT analyzed and coded the data with MK. MK, KT, and YM discussed the results until consensus was reached.

\section{References}

1. Glass RM. The patient-physician relationship: JAMA focuses on the center of medicine. JAMA. 1996;275(2):147-148.

2. Pedersen R. Empirical research on empathy in medicine: a critical review. Patient Educ Couns. 2009;76(3):307322 .

3. Hardy C. Empathizing with patients: the role of interaction and narratives in providing better patient care. Med Health Care Philos. 2017;20(2):237-248.

4. Weiss T, Swede MI. Transforming preprofessional health education through relationship-centered care and narrative medicine. Teach Learn Med. 2019;31(2):222-233.

5. Arnold L. Assessing professional behavior: yesterday, today, and tomorrow. Acad Med. 2002;77(6):502-515.

6. Hojat M. Ten approaches for enhancing empathy in health and human services cultures. J Health Hum Serv Adm. 2009;31(4):412-450.

7. Schrooten I, de Jong MD. If you could read my mind: the role of healthcare providers' empathic and communicative competencies in clients' satisfaction with consultations. Health Commun. 2017;32(1):111-118.

8. Trzeciak S, Roberts BW, Mazzarelli AJ. Compassionomics: hypothesis and experimental approach. Med Hypotheses. 2017;107:92-97.

9. Kim SS, Kaplowitz S, Johnston MV. The effects of physician empathy on patient satisfaction and compliance. Eval Health Prof. 2004;27(3):237-251.

10. Hojat M, Louis DZ, Markham FW, Wender R, Rabinowitz C, Gonnella JS. Physicians' empathy and clinical outcomes for diabetic patients. Acad Med. $2011 ; 86(3): 359-364$.
11. Kelm Z, Womer J, Walter JK, Feudtner C. Interventions to cultivate physician empathy: a systematic review. BMC Med Educ. 2014;14:219.

12. Scott H. Empathy in healthcare settings [dissertation]. London, UK: Goldsmiths, University of London; 2011

13. Hojat M. Empathy in patient care: antecedents, development, measurement, and outcomes. New York, USA: Springer Science \& Business Media; 2007.

14. Henry-Tillman R, Deloney LA, Savidge M, Graham CJ, Klimberg VS. The medical student as patient navigator as an approach to teaching empathy. Am J Surg. 2002; 183(6):659-662.

15. Spiro H. What is empathy and can it be taught? Ann Intern Med. 1992;116(10):843-846.

16. Marcus ER. Empathy, humanism, and the professionalization process of medical education. Acad Med. 1999;74(11):1211-1215.

17. Newton BW, Savidge MA, Barber L, et al. Differences in medical students' empathy. Acad Med. 2000;75(12): 1215.

18. Majumder MA, Ojeh N, Rahman S, Sa B. Empathy in medical education: can 'kindness' be taught, learned and assessed? Adv Hum Biol. 2020;10(2):38-40.

19. Bayne HB. Training medical students in empathic communication. J Spec Group Work. 2011;36(4):316329.

20. Karlowicz KA, Palmer KL. Engendering student empathy for disabled clients with urinary incontinence through experiential learning. Urol Nurs. 2006;26(5):373-378.

21. Bunn W, Terpstra J. Cultivating empathy for the mentally ill using simulated auditory hallucinations. Acad Psychiatry. 2009;33(6):457-460.

22. Wilkes M, Milgrom E, Hoffman JR. Towards more empathic medical students: a medical student hospitalization experience. Med Educ. 2002;36(6):528-533.

23. Kolb DA. Experiential learning: experience as the source of learning and development. Englewood Cliffs, USA: 
Prentice Hall; 1984.

24. Braun V, Clarke V. Using thematic analysis in psychology. Qual Res Psychol. 2006;3(2):77-101.

25. Wen D, Ma X, Li H, Liu Z, Xian B, Liu Y. Empathy in Chinese medical students: psychometric characteristics and differences by gender and year of medical education. BMC Med Educ. 2013;13:130.

26. Roh MS, Hahm BJ, Lee DH, Suh DH. Evaluation of empathy among Korean medical students: a crosssectional study using the Korean version of the Jefferson Scale of Physician Empathy. Teach Learn Med. 2010; 22(3):167-171.

27. Al-Eraky MM. Twelve tips for teaching medical professionalism at all levels of medical education. Med Teach. 2015;37(11):1018-1025.

28. Ohtaki S. Asymmetry in doctor-patient communication: a comparison between Japan and the USA. Jpn J Lang Soc. 2013;16(1):80-95.

29. Batt-Rawden SA, Chisolm MS, Anton B, Flickinger TE. Teaching empathy to medical students: an updated, systematic review. Acad Med. 2013;88(8):1171-1177.

30. Shapiro SM, Lancee WJ, Richards-Bentley CM. Evaluation of a communication skills program for first-year medical students at the University of Toronto. BMC Med Educ. 2009;9:11. 